УДК 631.348

(C) 2014

Іванов О. М., Арендаренко В. М., кандидати технічних наук

Полтавська державна аграрна академія

\title{
РОЗРАХУНКОВА МОДЕЛЬ ГІДРООБПРИСКУВАЛЬНОЇ УСТАНОВКИ ТУНЕЛЬНОГО ТИПУ
}

\section{Рецензент - кандидат технічних наук Р. М. Харак}

Наведено результати теоретичних досліджень зі складання розрахункової моделі гідрообприскувальної установки тунельного типу, призначеної для обприскування під високим тиском рослин у тунельній камеpi. Дослідження проводились із залученням теоріі гідродинаміки та гідростатики для розрахунку складних трубопроводів $і$ багатокомпонентних гідравлічних систем. За результатами розрахункових досліджень було складено аналітичні рівняння, щуо визначають величини гідравлічних параметрів у вузлових точках $і$ встановлюють взаємозв'язок між основними компонентами гідравлічної установки.

Ключові слова: трубопровід, гідравлічна система, гідростатика, форсунка, гідродинамічні параметри, розрахункова модель.

Постановка проблеми. Забезпечення населення високоякісною та екологічно чистою продукцією - основне завдання сільськогосподарського виробництва. Проте для отримання якісної продукції товаровиробники застосовують різноманітні отрутохімікати, які шляхом обприскування наносяться на рослини.

Обприскування насаджень картоплі виконується декілька разів (залежно від появи дорослих жуків та їх личинок). Для цього використовуються штангові обприскувачі, обладнанні форсунками. Таке обприскування передбачає розпилення робочої рідини на транспортування утворених крапель повітряним потоком до об'єктів обробки. У такому разі частина робочої рідини потрапляє на грунт, а інша $з$ бадилля картоплі стікає знову ж на грунт, збільшуючи його пестицидне навантаження.

Для усунення цього недоліку пропонується гідрооприскувальна установка тунельного типу, в якій відбувається обприскування насаджень картоплі у закритому об'ємі. Така схема обприскування забезпечує збір стікаючої робочої рідини та її повторне використання.

Аналіз останніх досліджень i публікацій, у яких започатковано розв'язання проблеми. Збиранням і знищенням колорадського жука на насадженнях картоплі займалися різні науковці. Так, у роботах [1-3] пропонується збирання шкідника пневматичним шляхом, а знищення його - механічним. Однак такий принцип не дає можливості збирати й знищувати личинок жука першого та другого поколінь.

Для вирішення проблеми збирання дорослих жуків та їх личинок нами запропоновано і запатентовано корисну модель України [6]. У запропонованій установці струшування личинок і дорослих жуків відбувається стисненим струменем робочої рідини. Установка складається з робочої камери П-подібного типу, форсунок, розміщених ярусно в середині робочої камери, насоса, бака, фільтрів, струминного насоса та трубопроводів.

Мета роботи і завдання досліджень. Метою запропонованого дослідження є складання розрахункової моделі гідравлічної системи тунельної обприскувальної установки з використанням основних положень теорій гідростатики та гідродинаміки для використання iï в подальших теоретичних дослідженнях із визначення та узгодження гідравлічних параметрів і характеристик основних складових даної установки.

Завданням запропонованого дослідження $€$ наведення чіткого математичного алгоритму для визначення гідропараметрів у вузлових точках конструкції зі складними трубопроводами та 3 різноманітними за характером і принципом дії гідравлічними елементами.

Результати дослідження. Принципова гідравлічна схема тунельної гідрообприскувальної установки відображена на рис. 1 а. Установка обладнана баком великого об'єму, з якого за допомогою відцентрового насоса відбувається відбір рідини та нагнітання іiі під високим тиском до великої кількості форсунок у камері для обприскування (рис. 1 б). Кількість форсунок та характер їхнього розташування в середині камери відповідає вимогам ефективного процесу обприскування. 3 метою економії обприскувальної рідини до складу установки входить збірний бак, використання якого дає змогу збирати й накопичувати ту частину рідини, що не потрапляє на об'єкт обприскування і природним шляхом стікає з поверхні цього об'єкта. Для відкачування 


\section{ТЕХНІЧНІ НАУКИ}

зібраної рідини до установки вводиться струминний насос та фільтр, який очищує потік рідини від механічних і рослинних домішок.

Інжекційним потоком струминного насоса $\epsilon$ відгалужена частина основного гідравлічного потоку, що подається штатним відцентровим насосом установки до форсунок камери обприскування.

Розв'язання завдання зі складання розрахункової моделі гідравлічної системи зі складними трубопроводами передбачає розбиття єдиної конструкції на елементарні частини, які б представляли собою комплекс простих трубопроводів і розрахунок яких зводиться до застосування закону (рівняння) Бернуллі [4] та рівняння нерозривності потоку робочої рідини.

У зв'язку 3 цим гідравлічна схема установки (рис. 1 а) розбита на окремі складові (рис. 2). Розглянемо кожну складову зокрема. Перша складова на рис. 2 а представляє собою гідравлічну штангу 3 кількома начепленими форсунками, що приєднана до вхідного вузла С.

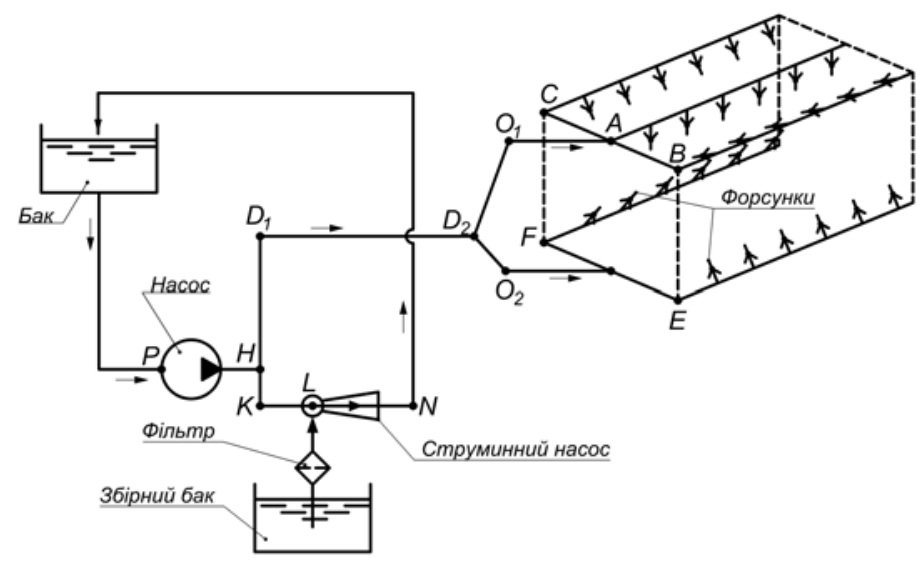

a)

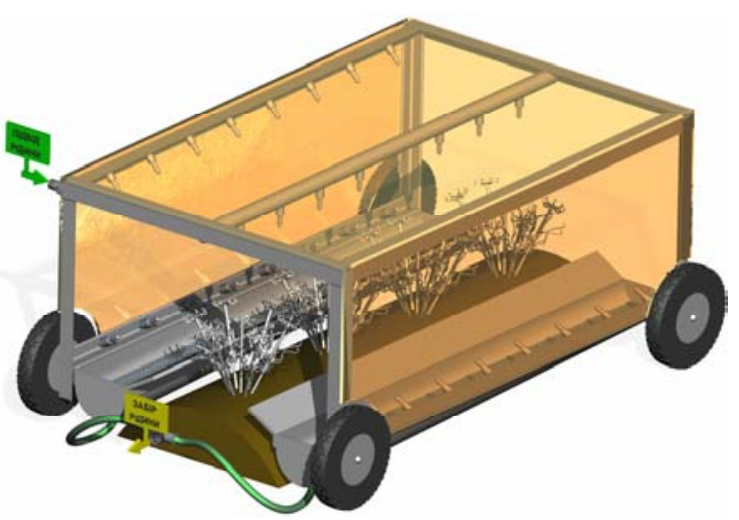

б)

Рис. 1. Принципова гідравлічна схема установки (а) та загальний вигляд ї̈ обприскувальної камери (б)
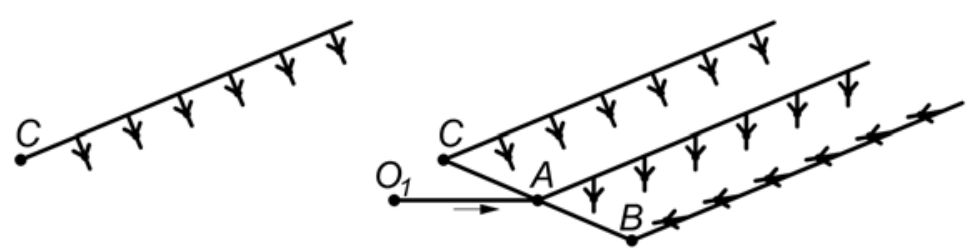

a)

б)

B)

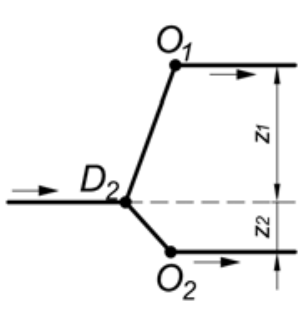

г)

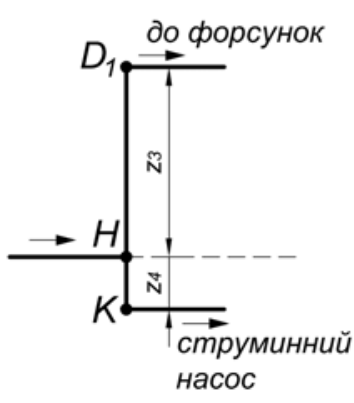

д)

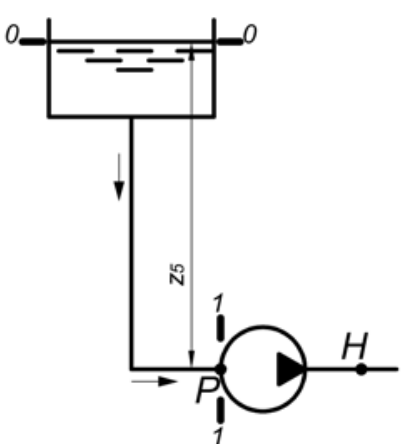

ж)

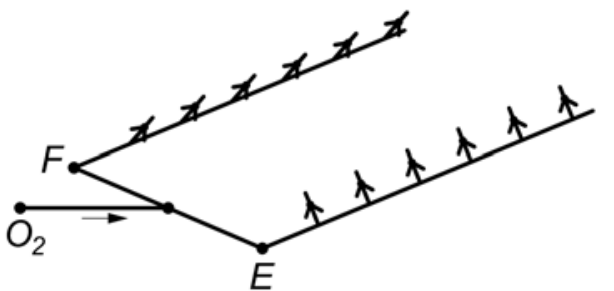

Рис. 2. Відокремленні компоненти гідравлічної системи 
Розрахуємо для даної вузлової точки гідравлічний тиск $\mathrm{pC}$ і величину витрати робочої рідини $\left(\mathrm{Q}_{\mathrm{C}}\right)$.

Сукупна величина витрати $\mathrm{Q}_{\mathrm{C}}$ визначається як сума витрат рідини через кожну форсунку, які приєднані до штанги [5]:

$$
Q_{C}=Q_{\phi_{1}}+Q_{\phi_{2}}+\ldots+Q_{\phi_{n}}
$$

де $Q_{\phi_{1}}, Q_{\phi_{n}}$ - величина витрати рідини через першу та n-ну форсунки.

Якщо форсунки є однотипними й мають однакові регулювання, то витрата рідини через кожну 3 них буде однакова. Тоді сумарна витрата $\mathrm{Q}_{\mathrm{C}}$ дорівнюватиме:

$$
Q_{C}=n \cdot Q_{\phi}
$$

де $\mathrm{n}$ - кількість форсунок на штанзі.

Для визначення величини тиску $\mathrm{pC}$ складемо рівняння Бернуллі для двох перерізів відносно площини порівняння, що проходить через точку C. Перший переріз проходить через точку $\mathrm{C}$, інший - через поперечний переріз вихідного сопла першої форсунки. Ваговими тисками нехтуємо, так як точка $\mathrm{C}$ i вихідне сопло форсунки лежать на одній горизонтальній площині. 3 урахуванням цього рівняння Бернуллі матиме вигляд:

$p_{c}+\frac{\rho}{2} v_{c}^{2}=p_{\text {amм }}+\frac{\rho}{2} v_{\phi_{1}}^{2}+\Delta p_{m p}+\Delta p_{\text {мiс }}$

Звідси тиск рС дорівнюватиме:

$p_{c}=p_{\text {amм }}+\frac{\rho}{2}\left(v_{\phi_{1}}^{2}-v_{c}^{2}\right)+\Delta p_{m p}+\Delta p_{\text {мic }}$

де: $p_{\text {атм - атмосферний тиск; }}$

$\rho$ - густина рідинного потоку;

$v_{\phi_{1}}$ - швидкість потоку у вихідному соплі форсунки;

$v_{c}$ - швидкість потоку в точці $\mathrm{C}$;

$\Delta p_{m p}$ - втрата тиску по довжині трубопроводу;

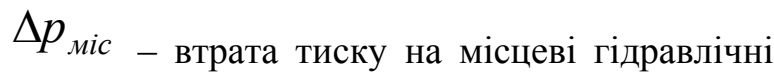
перешкоди.

Втрати тиску по довжині та на місцеві опори можуть бути знайдені за формулами Вейсбаха i Дарсі-Вейсбаха [5]:

$$
\Delta p_{m p}=\lambda \frac{\rho \cdot \ell}{2 \cdot d_{c}} \cdot v_{c}^{2}
$$

$$
\Delta p_{\text {мiс }}=\sum \zeta \cdot \frac{\rho \cdot v_{\phi_{1}}^{2}}{2}
$$

Втрата величини тиску $\Delta p_{\text {міс визначається }}$ як сукупні втрати енерії потоку рідини в середині форсунки при протіканні його від точки С до вихідного кінця сопла.

Зробимо деякі спрощення аналітичного виразу, що визначає витрату рідини в певному перерізі трубопроводу, визначимо величину швидкості руху потоку [4]:

$$
v=\frac{Q}{S}=\frac{4 Q}{\pi d^{2}} \text {. }
$$

Тоді формули (5) та (6) матимуть вигляд:

$$
\begin{aligned}
\Delta p_{m p} & =\lambda \frac{8 \cdot \rho \cdot \ell}{\pi^{2} \cdot d_{c}^{5}} \cdot Q_{c}^{2} \\
\Delta p_{\text {Mic }} & =\sum \zeta \cdot \frac{8 \cdot \rho}{\pi^{2} \cdot d_{\phi_{1}}^{4}} \cdot Q_{\phi_{1}}^{2}
\end{aligned}
$$

У рівняннях (5), (6), (8), (9) виконаємо наступні заміни:

$$
\begin{aligned}
& C_{\phi}=\frac{8 \cdot \rho}{\pi^{2} \cdot d_{\phi_{1}}^{4}} \\
& C_{c}=\frac{8 \cdot \rho}{\pi^{2} \cdot d_{c}^{4}} \\
& K_{C}=\lambda \frac{8 \cdot \rho \cdot \ell}{\pi^{2} \cdot d_{c}^{5}} \\
& K_{\phi}=\sum \zeta \cdot \frac{8 \cdot \rho}{\pi^{2} \cdot d_{\phi_{1}}^{4}}
\end{aligned}
$$

3 урахуванням вищезазначених замін, формула (4) набуде наступного вигляду:

$$
p_{c}=p_{\text {amu }}+C_{\phi_{1}} \cdot Q_{\phi_{1}}^{2}-C_{c} \cdot Q_{c}^{2}+K_{c} \cdot Q_{c}^{2}+K_{\phi_{1}} \cdot Q_{\phi_{1}}^{2}
$$

Об'єднавши всі спільні складові рівняння (14) та ввівши нижче наведені заміни,

$$
\begin{aligned}
& Z_{\phi}=C_{\phi_{1}}+K_{\phi_{1}} ; \\
& Y_{c}=K_{C}-C_{C} .
\end{aligned}
$$

остаточне рівняння величини гідравлічного тиску рС матиме форму:

$$
p_{c}=p_{\text {ams }}+Z_{\phi} \cdot Q_{\phi_{1}}^{2}-Y_{c} \cdot Q_{c}^{2}
$$

Аналогічним чином складаються рівняння гідравлічного тиску рС по відношенню до інших форсунок. У загальному випадку тиск рС буде 
визначатися через систему однотипних рівнянь, складених для кожної з форсунок.

Знехтуємо величиною втрати гідравлічного тиску по довжині трубопроводів від точки С до окремо взятої форсунок (несуттєвого значення для даної гідравлічної схеми). Тоді величина тиску рС буде визначатися лише рівнянням (17).

Таким чином, наведена нижче система рівнянь у повній мірі визначає всі шукані гідравлічні параметри для точки $\mathrm{C}$ :

$$
\left\{\begin{array}{l}
Q_{C}=n \cdot Q_{\phi} \\
p_{c}=p_{a m u}+Z_{\phi} \cdot Q_{\phi}^{2}-Y_{c} \cdot Q_{c}^{2} .
\end{array}\right.
$$

Використавши наведену вище методику, визначаємо необхідні гідравлічні параметри для точок А та В (рис. 2 б):

$$
\begin{aligned}
& \left\{\begin{array}{l}
Q_{A}=n \cdot Q_{\phi} ; \\
p_{A}=p_{a m \mu}+Z_{\phi} \cdot Q_{\phi}^{2}-Y_{A} \cdot Q_{A}^{2} .
\end{array}\right. \\
& \left\{\begin{array}{l}
Q_{B}=n \cdot Q_{\phi} ; \\
p_{B}=p_{a m \mu}+Z_{\phi} \cdot Q_{\phi}^{2}-Y_{B} \cdot Q_{B}^{2} .
\end{array}\right.
\end{aligned}
$$

Перейдемо до обрахунків у точці $\mathrm{O}_{1}$ (рис. 2 б).

Оскільки точка $\mathrm{O}_{1} \epsilon$ спільним входом для точок A, В і C, то витрата $Q_{1}$ буде визначатися за наступним виразом:

$$
Q_{O_{1}}=Q_{A}+Q_{B}+Q_{C} \text {. }
$$
$\mathrm{C}$

3 умови однаковості витрати через точки A, B,

$$
Q_{A}=Q_{B}=Q_{C} .
$$

Витрата $Q_{O_{1}}$ буде обраховуватися:

$$
Q_{O_{1}}=n \cdot Q_{A}
$$

де $\mathrm{n}$ - кількість вихідних ліній із точки $\mathrm{O}_{1} 3$ однаковою витратою.

Відповідно до рівняння Бернуллі тиск $p_{O_{1}}$ визначатиметься:

$$
p_{O_{1}}=p_{A}+\rho \cdot g \cdot \sum \zeta_{O_{1} A} \cdot \frac{8 \cdot \rho}{\pi^{2} \cdot d_{A}^{4}} \cdot Q_{A}^{2},
$$

де $\sum \zeta_{O_{1} A}$ - сукупний коефіцієнт втрат тиску на переході від точки $\mathrm{O}_{1}$ до точки А.

Для спрощення виразу зробимо наступну заміну:

$$
Z_{A}=\sum \zeta_{O_{1} A} \cdot \frac{8 \cdot g \cdot \rho^{2}}{\pi^{2} \cdot d_{A}^{4}}
$$

Тоді тиск у точці $\mathrm{O}_{1}$ буде визначатися:

$$
p_{O_{1}}=p_{A}+Z_{A} \cdot Q_{A}^{2} \text {. }
$$

Складання рівняння (26) по відношенню до точок В та С здійснюється за наведеним вище способом. Тоді величина тиску $p_{O_{1}}$ буде визначатися наступною системою рівнянь:

$$
\left\{\begin{array}{l}
p_{O_{1}}=p_{A}+Z_{A} \cdot Q_{A}^{2} \\
p_{O_{1}}=p_{B}+Z_{B} \cdot Q_{B}^{2} \\
p_{O_{1}}=p_{C}+Z_{C} \cdot Q_{C}^{2}
\end{array}\right.
$$

Для точки $\mathrm{O}_{1}$ обрахунок гідравлічних параметрів здійснюється за системою:

$$
\left\{\begin{array}{l}
Q_{O_{1}}=n \cdot Q_{A} \\
p_{O_{1}}=p_{A}+Z_{A} \cdot Q_{A}^{2} \\
p_{O_{1}}=p_{B}+Z_{B} \cdot Q_{B}^{2} \\
p_{O_{1}}=p_{C}+Z_{C} \cdot Q_{C}^{2}
\end{array}\right.
$$

Методика складання систем рівнянь для нижнього ряду форсунок (рис. 2 в) та вузлових точок $\mathrm{F}, \mathrm{E}, \mathrm{O}_{2} \epsilon$ відповідною, тому наведемо лише остаточні результати:

Точка F:

$\left\{\begin{array}{l}Q_{F}=n \cdot Q_{\phi} ; \\ p_{F}=p_{a m u}+Z_{\phi} \cdot Q_{\phi}^{2}-Y_{F} \cdot Q_{F}^{2} .\end{array}\right.$

Точка E:

$\left\{\begin{array}{l}Q_{E}=n \cdot Q_{\phi} ; \\ p_{E}=p_{a m \mu}+Z_{\phi} \cdot Q_{\phi}^{2}-Y_{E} \cdot Q_{E}^{2} .\end{array}\right.$

Точка $\mathrm{O}_{2}$ :

$\left\{\begin{array}{l}Q_{O_{2}}=n \cdot Q_{E} \\ p_{O_{2}}=p_{E}+Z_{E} \cdot Q_{E}^{2} \\ p_{O_{2}}=p_{F}+Z_{F} \cdot Q_{F}^{2}\end{array}\right.$.

Для точки $\mathrm{D}_{2}$ (рис. 2 г) врахуємо висотність розташування вихідних точок $\mathrm{O}_{1}$ та $\mathrm{O}_{2}$ і прийнявши за основу вищевикладену методику обрахунку гідравлічних параметрів, зокрема для точки $\mathrm{O}_{2}$, отримаємо:

$$
\left\{\begin{array}{l}
Q_{D_{2}}=Q_{O_{1}}+Q_{O_{2}} \\
p_{D_{2}}=\rho g z_{1}+p_{O_{1}}+Z_{O_{1}} \cdot Q_{O_{1}}^{2} \\
p_{D_{2}}=-\rho g z_{2}+p_{O_{2}}+Z_{O_{2}} \cdot Q_{O_{2}}^{2}
\end{array} .\right.
$$


Однотипним до точки $\mathrm{D} \epsilon$ розрахунок гідравлічного тиску та витрати і для точки Н (рис. 2 д). Для неї система рівнянь матиме вигляд:

$$
\left\{\begin{array}{l}
Q_{H}=Q_{D_{1}}+Q_{K} \\
p_{H}=\rho g z_{3}+p_{D_{1}}+Z_{D_{1}} \cdot Q_{D_{1}}^{2} \\
p_{H}=-\rho g z_{4}+p_{K}+Z_{K} \cdot Q_{K}^{2} .
\end{array}\right.
$$

Визначимо потрібну величину тиску, яку необхідно створити відцентровому насосу для задоволення потреби в отримані належної величини тиску (витрати рідини) через форсунки з урахуванням усіх гідравлічних втрат у системі.

Як відомо, величина тиску насосу визначається як різниця енергії потоків рідини між його виходом та входом:

$$
p_{\text {насос }}=E_{\text {вих }}-E_{\text {вx }} \text {. }
$$

Вихідна енергія потоку має вираз:

$$
E_{\text {вих }}=p_{H}+\frac{\rho}{2} v_{H}^{2}
$$

Значення тиску $p_{H}$ та швидкості (витрати) рідини $v_{H}$ визначається з системи рівнянь (33).

Для знаходження енергії потоку рідини на вході складемо рівняння Бернуллі для двох перерізів 0-0 та 1-1 (рис. 2 е):

$$
\begin{aligned}
& p_{\text {атм }}-\rho \cdot g \cdot z_{5}=p_{1}+\frac{\rho}{2} v_{P}^{2}+\Delta p_{\text {мiс. }} \\
& \text { Тоді } E_{\text {вx }}: \\
& E_{\text {вx }}=p_{P}+\frac{\rho}{2} v_{P}^{2}=p_{\text {атм }}-\rho \cdot g \cdot z_{5}-\Delta p_{\text {мiс. }} .
\end{aligned}
$$
(25). (25).

Так як діаметри трубопроводів $d_{N}=d_{\text {виx }}$, то i $v_{N}=v_{\text {виx }}$, внаслідок чого величина потрібного тиску буде виражатися рівнянням:

$$
p_{N}=\rho \cdot g \cdot z_{7}+p_{\text {атм }}+\Delta p_{\text {мiс. }}
$$

Для струминного насоса величина вихідної подачі є сумою витрат робочої та всмоктувальної рідини:

$$
Q_{N}=Q_{K}+Q_{F}
$$

Для вихідного перерізу струминного насоса:

$$
\left\{\begin{array}{l}
Q_{N}=Q_{K}+Q_{L} ; \\
p_{N}=\rho \cdot g \cdot z_{7}+p_{\text {amм }}+Z_{N} \cdot Q_{N}^{2} .
\end{array}\right.
$$

Коефіцієнт $Z_{N}$ обраховується за формулою

Здійснимо розрахунок всмоктувальної лінії струминного насоса для визначення можливого рівня тиску для відсмоктування рідини з баку. Для цього цілей використаємо рівняння Бернуллі для вхідного перерізу всмоктувальної лінії насоca (точка L (рис. 2 ж)) та вільною поверхнею збірного баку. Після незначних перетворень та скорочень величина тиску дорівнюватиме:

$$
p_{L}=-\rho \cdot g \cdot z_{6}+p_{\text {amм }}-Z_{L} \cdot Q_{L}^{2}
$$

Коефіцієнт $Z_{L}$ обраховується за формулою

Продуктивність струминного насосу за всмоктувальною лінію визначаться за формулою:

$$
Q_{L}=\frac{\pi d_{B x}^{2}}{4} \cdot \sqrt{\frac{2}{\rho}\left(p_{\text {amм }}-p_{L}\right)}
$$

Необхідна величина тиску насоса визначається наступним рівнянням:

$p_{\text {насос }}=E_{\text {вих }}-E_{\text {вx }}=p_{H}+\frac{\rho}{2} v_{H}^{2}-p_{\text {aтм }}+\rho \cdot g \cdot z_{5}+\Delta p_{\text {мiс }}$

Використовуючи знання про потрібний вихідний тиск і витрату рідини, можна за допомогою напірних характеристик підібрати необхідний відцентровий нагнітальний насос.

Для струминного насоса (рис. 2 е) визначимо потрібний тиск на виході, необхідний для перекачки зібраної рідини в збірному баку до основного баку установки. Для цього складемо рівняння Бернуллі для вільної поверхні рідини в баку та площиною вихідного патрубка струминного насосу (точка $\mathrm{N}$ ):

$p_{N}+\frac{\rho}{2} \cdot v_{N}^{2}=\rho \cdot g \cdot z_{7}+p_{\text {amu }}+\frac{\rho}{2} v_{\text {вux }}^{2}+\Delta p_{\text {мic. }}$
Об'єднавши знайдені вище гідравлічні параметри, отримаємо кінцеву систему розрахункових рівнянь:

$$
\left\{\begin{array}{l}
Q_{L}=\frac{\pi d_{B x}^{2}}{4} \cdot \sqrt{\frac{2}{\rho}\left(p_{\text {amм }}-p_{L}\right)} ; \\
p_{L}=-\rho \cdot g \cdot z_{6}+p_{\text {amм }}-Z_{L} \cdot Q_{L}^{2} .
\end{array}\right.
$$

На підставі отриманих значень тисків на виході зі струминного насоса та у всмоктувальній лінії можна визначитися на основі положень теорії струминних апаратів із конструкцією й типом його звужуючого елемента.

Висновок. Наведений математичний алгоритм розрахунку гідравлічних параметрів в основних вузлових точках гідравлічної системи тунельної обприскувальної установки дасть змогу краще зрозуміти процеси, що відбуваються в ній, а також дати аргументовану оцінку якості іiі функціонування. 
Крім того розроблена модель дасть можливість підібрати необхідний нагнітальний і струминний насоси, які б задовольняли необхідні

\section{БІБЛІОГРАФІЯ}

1. Арендаренко В. М. Використання технічних засобів при збиранні та знищенні колорадського жука / В. М. Арендаренко. - Монографія. - Кременчук : ПП Щербатих О.В. - 2012. - 132 с.

2. А.С. 1685347 СССР А1, МКИ А01М5/08 Устройство для сбора насекомых с растений / Эргашов К., Алимухамедов С. Н., Жуйков Н. В., Кадыров А. К., Хакимов А. К., Болтабаев Ю. (СССР). - №449410/15; Опубл. 23.10.91, Бюл. №39. - С. 6.

3. Гуизол Т.Д. Обгрунтування параметрів та режимів роботи пристрою для механічного збирання комах-шкідників просапних сільськогосподарських культур : автореф. дис. ... канд. техн. наук: 05.05.11 - «Машини і засоби механі- технологічні потреби та вимоги щодо забезпечення ефективної роботи гідрообприскувальної установки.

зації сільськогосподарського виробництва» / Тарас Дмитрович Гуцол. - Львів, 2007. - 19 с.

4. Закон Бернулли / Википедия. Свободная энциклопедия [Електронний ресурс]. - Режим доступу: http://ru.wikipedia.org/wiki/Закон_Бернулли.

5. Лупина Т. А. Гидравлический расчет напорных трубопроводов / Т. А. Лупина, К. В. Симонов. - М.: МИИТ, 2008. - 214 с.

6. Патент на корисну модель UA 360034 України, кл. А01 М5/05. Установка для збирання та знищення колорадського жука АСЖ-1 / Арендаренко В. М., Е. Я. Прасолов, О. П. Слинько, Р. М. Харак, С. А. Браженко, Л.В.Знова, В.А.Шенель, С.В.Гладкий, О. О. Багмен, Д. О. Швець (Україна). - №200806109; заявл. 12.05.08; опубл. 10.10.08, Бюл. №19. 